\title{
PEGAMENTO DE FRUTOS EM PEPINO CAIPIRA NÃO PARTENOCÁRPICO SOB CULTIVO PROTEGIDO COM APLICAÇÃO DE ÁCIDO NAFTALENO ACÉTICO(1)
}

\author{
AMANDA REGINA GODOY(2); ANTONO ISMAEL INÁCIO CARDOSO ${ }^{(2)}$
}

\begin{abstract}
RESUMO
Os experimentos foram realizados para verificar a possibilidade de aumentar o pegamento de frutos de pepino caipira (Cucumis sativus) ginóico não partenocárpico (híbrido Guarani AG - 370), cultivado sob ambiente protegido, através da aplicação de ácido naftaleno acético (ANA). No primeiro experimento foram avaliados sete tratamentos resultantes da combinação de dois fatores: doses de ANA $\left(25,50\right.$ e $\left.100 \mathrm{mg} . \mathrm{L}^{-1}\right)$ e dois intervalos de aplicação na planta inteira (a cada sete ou quatorze dias), além da testemunha sem aplicação de qualquer produto. O delineamento foi em blocos ao acaso, com seis repetições e quatro plantas por parcela. No segundo experimento foram avaliados quatro tratamentos, sendo aplicação na flor no dia de sua antese com diferentes doses de ANA (25, 50 e $\left.100 \mathrm{mg} . \mathrm{L}^{-1}\right)$, além da testemunha sem aplicação de qualquer produto. O delineamento foi em blocos ao acaso, com seis repetições e quatro plantas por parcela. No terceiro experimento foram avaliados quatro tratamentos, sendo aplicação na flor no dia de sua antese com diferentes doses de ANA (100, 200 e $\left.400 \mathrm{mg} . \mathrm{L}^{-1}\right)$, além da testemunha sem aplicação de qualquer produto. O delineamento foi em blocos ao acaso, com cinco repetições e cinco plantas por parcela. Os resultados mostraram que nos tratamentos com aplicação na planta inteira não houve pegamento de frutos, independentemente da dose e do intervalo de aplicação, e nos tratamentos com aplicação na flor houve aumento no pegamento de frutos, sendo crescente com o aumento da dose até $200 \mathrm{mg} . \mathrm{L}^{-1}$ de ANA, quando se obteve $38 \%$ de pegamento das flores tratadas.
\end{abstract}

Palavras-chave: Cucumis sativus, partenocarpia, auxina, cultivo protegido.

\section{ABSTRACT \\ FRUIT SETTING IN NON-PARTENOCARPIC “CAIPIRA” CUCUMBER CULTIVATED UNDER PROTECTED CULTIVATION WITH NAA SPRAYING}

In order to verify the possibility of increasing fruit seting in non-partenocarpic "caipira" type cucumber (hybrid Guarani AG-370) through NAA spraying, three trails were performed. In trial 1, seven treatments, resulted from two factors combination: three NAA levels (25, 50 and $100 \mathrm{mg}$. $\mathrm{L}^{-1}$ ) and two spraying intervals in whole plant (each 7 or 14 days), besides control without any spraying, were evaluated. There were six replicates of four plants per plot in a randomized block design. In trial 2, four treatments, NAA aplication on flower at anthesis with 25, 50 and $100 \mathrm{mg} . \mathrm{L}^{-1}$, were evaluated in a randomized block

$\left({ }^{1}\right)$ Recebido para publicação em 29 de agosto de 2002 e aceito em 23 de outubro de 2003.

$\left(^{2}\right)$ Departamento de Produção Vegetal, Faculdade de Ciências Agronômicas - UNESP, Caixa Postal 237, 18603-970 Botucatu (SP). E-mail: ismaeldh@fca.unesp.br 
design with six replicates of four plants per plot. In trial 3, four treatments, NAA aplication on flower at anthesis with 100, 200 and $400 \mathrm{mg} . \mathrm{L}^{-1}$, were evaluated in a randomized block design with five replicates of five plants per plot. There was no fruit seting increasing with whole plant spraying, in any level or day interval. However, there was fruit seting increasing with flower spraying, until $200 \mathrm{mg} . \mathrm{l}^{-1}$ of NAA, when $38 \%$ of fruit setting was achieved.

Key words: Cucumis sativus, parthenocarpy, auxin, protected cultivation.

\section{INTRODUÇÃO}

A partenocarpia é bastante comum em plantas com numerosos óvulos por fruto, como abacaxi, melão, tomate, etc. Fatores ambientais podem causar partenocarpia, e em pepino (Cucumis sativus) dias curtos e baixas temperaturas noturnas estimulam o desenvolvimento de frutos partenocárpicos (FERRI, 1979).

Após a descoberta das auxinas, verificou-se que o crescimento do fruto de muitas espécies poderia ser induzido sem polinização, ou seja, partenocarpicamente, se tratados com auxina. O estímulo de auxina não provém apenas do pólen, mas também do ovário. Algum fator do pólen estimula a síntese de auxina pelo ovário e esta síntese segue um padrão progressivo do estilete para o ovário (FERRI, 1979).

O uso de Agritone $(0,43 \%$ de ANA $+1,18 \%$ naphtaleneacetamide) na dose de $80 \mathrm{~g} .100 \mathrm{~L}^{-1}$ em solução, aplicado na ocasião do florescimento e, semanalmente, até a 9. ${ }^{\text {a }}$ semana de idade das plantas de abobrinha, aumentou a produção e o tamanho dos frutos, o número de frutos sem sementes, melhorou o pegamento e diminuiu o número de flores abortadas (Suleiman e Suwwan, 1990).

Para suprir a deficiência de pegamento de frutos, Amarante et al. (2000) usando doses de 150, 300, 450, 600 e $750 \mathrm{mg} . \mathrm{L}^{-1}$ de ANA em flores recém-abertas de abóbora híbrida 'Tetsukabuto', obtiveram frutos com desenvolvimento similar aos oriundos da polinização natural nas doses de 150 a $600 \mathrm{mg} \cdot \mathrm{L}^{-1}$; na dose maior $\left(750 \mathrm{mg} . \mathrm{L}^{-1}\right)$, o índice de pegamento de frutos caiu drasticamente.

CANTLiffe et al. (1972) obtiveram aumento no número de frutos por planta em pepino com aplicação combinada de etephon e chlorflurenol, ou seja, o primeiro induziu o aumento no número de flores femininas e o segundo, o de frutos partenocárpicos. Entretanto, Gustafsen (1936) e Bini e Raddi (1965), citados por Cantliffe et al. (1972) relataram o desenvolvimento de frutos partenocárpicos em pepino com aplicação de ANA.

A maioria dos híbridos de pepino do tipo japonês plantados no Brasil é partenocárpico, por isso podem ser cultivados em ambiente protegido o ano todo. Já cultivares e híbridos de pepino caipira não apresentam partenocarpia, o que dificulta seu plantio no inverno em estufas fechadas, devido às limitações à entrada de insetos polinizadores. A produção também diminui quando a população de insetos polinizadores é pequena.

O objetivo dste trabalho foi verificar a possibilidade de aumentar o pegamento de frutos de pepino tipo caipira ginóico não partenocárpico, sob ambiente protegido, mediante a aplicação de ANA.

\section{MATERIAL E MÉTODOS}

Os experimentos foram desenvolvidos nas dependências do Departamento de Produção Vegetal, Setor de Horticultura, na Fazenda Experimental do Lageado, localizada no município de Botucatu (SP), pertencente à Faculdade de Ciências Agronômicas (FCA), da Universidade Estadual Paulista (UNESP), Campus de Botucatu. Os experimentos foram realizados em estufa do tipo arco, com $7 \mathrm{~m}$ de largura por 20 $\mathrm{m}$ de comprimento e pé direito de $1,8 \mathrm{~m}$.

Como garantia de ausência de polinização, foram utilizadas somente as plantas ginóicas do híbrido não partenocárpico Guarani AG-370. Como fonte de auxina foi aplicado o produto Raizon que contém $20 \%$ de ANA.

Foram produzidas mudas em bandejas de poliestireno expandido de 128 células, e transplantadas para vasos (uma planta por vaso) com capacidade para $13,3 \mathrm{~L}$ de substrato $(85 \%$ de solo $+5 \%$ de esterco de galinha $+10 \%$ de palha de arroz carbonizada), em um espaçamento de 1,0 m entre linha de vasos e 0,5 $m$ entre o centro de cada vaso.

Cada planta foi tutorada individualmente e eliminadas todas as brotações e flores até o quinto nó da haste principal. A partir do sexto nó da haste principal foram deixadas as brotações laterais.

Nessas brotações laterais, as desbrotas foram realizadas entre a segunda e terceira folhas definitivas. A retirada do meristema apical foi feita quando a planta atingiu a altura do arame (cerca de $1,8 \mathrm{~m}$ de altura). 


\subsection{Experimento 1}

Nesse experimento, a aplicação de ANA foi realizada na planta inteira com início em 30 de janeiro de 2001, quando ocorreu a abertura das primeiras flores de cada parcela a ser tratada. Foram avaliados sete tratamentos resultantes de dois fatores: doses de ANA $\left(25,50\right.$ e $\left.100 \mathrm{mg} . \mathrm{L}^{-1}\right)$ e intervalo de aplicação na planta inteira (a cada sete ou quatorze dias), além da testemunha sem aplicação de qualquer produto.

O experimento abrangeu seis repetições, em um delineamento em blocos ao acaso, com quatro plantas por parcela. Os frutos que se desenvolveram foram colhidos (com cerca de $15 \mathrm{~cm}$ de comprimento), obtendo-se a produção de frutos por planta.

Realizou-se análise de variância para as características de produção (número e massa) de frutos por planta. As comparações das médias foram feitas pelo teste de Tukey a 5\% de probabilidade.

\subsection{Experimento 2}

Foram aproveitadas somente as flores femininas recém-abertas no momento em que os tratamentos foram aplicados, sendo as demais eliminadas. Foram tratadas cerca de 30 a 40 flores por parcela. Foram comparadas três doses de ANA (25, 50 e $\left.100 \mathrm{mg} . \mathrm{L}^{-1}\right)$ com aplicação na flor, além da testemunha sem aplicação de qualquer produto. A aplicação foi realizada individualmente em cada flor, no dia da antese, iniciando-se em 30 de janeiro de 2001.

O experimento abrangeu seis repetições, em um delineamento em blocos ao acaso, com quatro plantas por parcela. Os frutos que se desenvolveram foram colhidos com cerca de $15 \mathrm{~cm}$ de comprimento, obtendo-se a porcentagem de pegamento de frutos.

\subsection{Experimento 3}

A aplicação iniciou-se no dia 29 de maio de 2001. Foram aproveitadas somente as flores femininas recém-abertas no momento em que os tratamentos foram aplicados, sendo as demais eliminadas. Foram comparadas três doses de ANA (100, 200 e 400 mg.L $\mathrm{L}^{-1}$ ), aplicadas na flor, além da testemunha sem aplicação de qualquer produto. Esses tratamentos foram definidos após observação dos resultados do experimento anterior.

O experimento abrangeu cinco repetições, em um delineamento em blocos ao acaso, com cinco plantas por parcela. Os frutos que se desenvolveram foram colhidos com cerca de $15 \mathrm{~cm}$ de comprimento, obtendo-se a porcentagem de pegamento de frutos.
Realizou-se análise de variância conjunta dos experimentos 2 e 3 e, a seguir, uma análise de regressão.

\section{RESULTADOS E DISCUSSÃO}

\subsection{Experimento 1}

Para as características relacionadas à produção de frutos (número e massa) não se obteve interação significativa entre doses de ANA e períodos de aplicação. Verificou-se que os tratamentos com aplicação na planta inteira, tanto a cada sete dias como quatorze, não diferiram da testemunha, significando que não houve pegamento de fruto, e a aplicação de ANA na planta inteira não foi vantajosa em qualquer das doses aplicadas $(25,50$ e 100 $\left.\mathrm{mg} . \mathrm{L}^{-1}\right)$. Esse resultado comprova o efeito da auxina em órgãos e tecidos isolados e não em plantas intactas.

A média de frutos nesses tratamentos foi de 1,9 fruto por planta, que pode ser resultado de polinização com pólen de outro plantio de pepino na região, já que a estufa não era totalmente fechada. Algumas plantas também emitiram flores masculinas em pequena quantidade, que eram eliminadas, mas também podem ter contribuído para esse pegamento de frutos. Mesmo plantas ginóicas podem produzir flores masculinas sob condições de alta temperatura e luminosidade (KoOIstra, 1967; CANTliffe, 1981).

Observou-se que, quando aplicado o ANA na planta inteira, independentemente da dose, as folhas apresentavam-se retorcidas e viradas para baixo, sendo esse feito maior nas plantas com aplicação a cada sete dias, principalmente nas doses mais elevadas. $\mathrm{O}$ sintoma é conhecido como epinastia e pode ocorrer quando uma auxina é aplicada à superfície superior da folha. A epinastia é um efeito fisiológico ligado ao hormônio etileno, sendo o efeito da auxina indireto (TAIZ e ZeIger, 2002).

\subsection{Experimentos 2 e 3}

Quando a aplicação de ANA foi realizada direcionada à flor, observou-se um aumento crescente no pegamento de frutos passando de $10 \%$ com 25 mg. $\mathrm{L}^{-1}$ para $38 \%$ com $200 \mathrm{mg}$. $\mathrm{L}^{-1}$. Quando se utilizou $400 \mathrm{mg} . \mathrm{L}^{-1}$ houve um decréscimo no pegamento, sendo essa dose acima do ideal. Esse fato parece confirmar as observações de que altas doses de auxina podem induzir a síntese de etileno, que apresenta como principais efeitos biológicos a senescência e abscissão das flores (SAlisbury e Ross, 1992). 


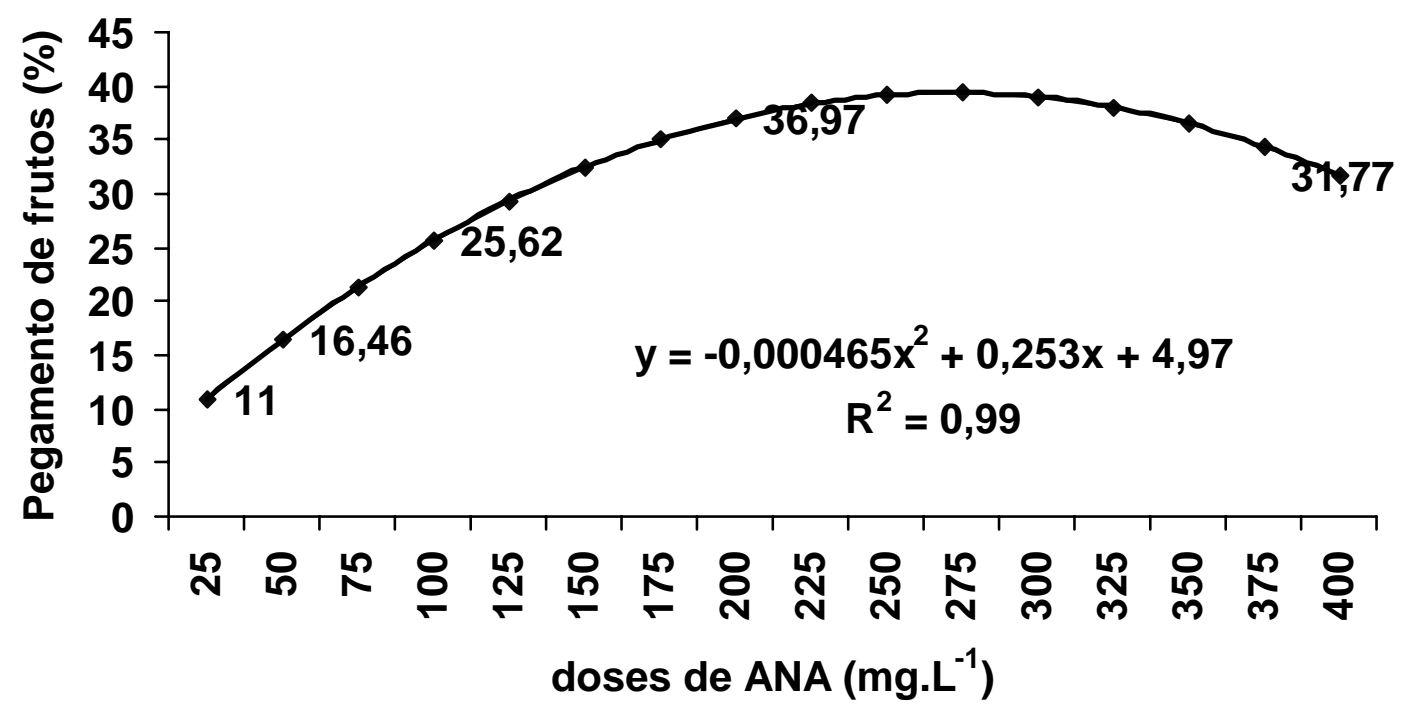

Figura 1. Porcentagem de pegamento de frutos em função da dose de ANA (mg. - $^{-1}$ ) aplicadas na flor. FCA/UNESP, Botucatu (SP), 2001.

Considerando-se a regressão obtida (Figura 1), pode-se estimar que, para as condições desse trabalho a melhor dose seria de $272 \mathrm{mg} . \mathrm{L}^{-1}$ com uma taxa de pegamento de $39,38 \%$.

Considerando-se que a antese de flores individuais em pepino é restrita a apenas um dia, no período da manhã, e que ocorre abortamento, caso estas não sejam polinizadas, é de fundamental importância a eficiente polinização das flores.

Em situações quando a polinização é prejudicada, por condições climáticas adversas para os insetos polinizadores ou pela impossibilidade de entrada pelo fechamento das laterais da estufa, pode-se prejudicar o pegamento de frutos e a produtividade da cultura.

Na ausência de polinização, o ovário abscide e a flor cai. Portanto, a polinização fornece o estímulo hormonal, principalmente na forma de auxinas, para o desenvolvimento do ovário e o pegamento dos frutos (KRISHNAMOORTHY, 1981).

A aplicação de auxinas sintéticas promove o desenvolvimento de frutos partenocárpicos (desprovidos de semente), isto é, formados na ausência de fecundação. Nesse caso, a auxina sintética substitui o suprimento endógeno de auxina do ovário fertilizado para o desenvolvimento do fruto (KrishnAmOORTHY, 1981; WitTWER, 1983).

A porcentagem de pegamento poderia ser maior se os frutos em desenvolvimento não provocassem o aborto de frutos novos. É comum, em pepino, que frutos em desenvolvimento retardem o crescimento ou mesmo provoquem aborto de frutos mais novos (Stigter, 1969; Marcelis, 1993), embora frutos partenocárpicos apresentem menor poder de competição e inibição (DENNA, 1973).

\section{CONCLUSÕES}

1. Nos tratamentos com aplicação na planta inteira, não houve pegamento de frutos independentemente da dose de ANA utilizada.

2. Com aplicação na flor, houve pegamento de frutos, sendo a maior porcentagem estimativa com a dose de $272 \mathrm{mg} . \mathrm{L}^{-1}$, com estimativa de $39,4 \%$ de pegamento.

\section{AGRADECIMENTOS}

Os autores agradecem à FAPESP pela concessão de bolsa de Iniciação Científica à primeira autora (processo 00/09199-4) e auxílio financeiro ao projeto (processo 00/09200-2).

\section{REFERÊNCIAS}

AMARANTE, C.V.T. do; MACEDO, A.F. de; ARRUDA, A.E. Frutificação e crescimento de frutos em abóbora híbrida 'Tetsukabuto' tratada com alfa-naftalenoacetato de sódio. Horticultura Brasileira, Brasília, v.18, n.3, p.212-214, 2000. 
CANTLIFFE, D.J. Alteration of sex expression in cucumber due to changes in temperature, light intensity, and photoperiod. Journal of American Society for Horticultural Science, Alexandria, v.106, n.2, p.133-136, 1981.

CANTLIFFE, D.J.; ROBINSON, R.W.; SHANNON S. Promotion of cucumber fruit set and development by chlorflurenol. HortScience, Alexandria, v.7, p.416-418, 1972.

DENNA, D.W. Effects of genetic parthenocarpy and gynoecious flowering habit on fruit production and growth of cucumber. Journal of American Society for Horticultural Science, Alexandria, v.98, n.6, p.602-604, 1973.

FERRI, M.G. Fisiologia vegetal 2. São Paulo: Editora da Universidade de São Paulo, 1979. v.2, 392p.

FNP Consultoria \& Comércio. Agrianual 2000. São Paulo, 2000.546p.

KRISHNAMOORTHY, H.N. Plant growth substances. New Delhi: McGraw-Hill, 1981. 214p.

KOOISTRA, E. Femaleness in breeding glasshouse cucumbers. Euphytica, Dordrecht, v.16, n.1, p.11-17, 1967.
MARCELIS, L.F.M. Effect of assimilate supply on the growth of individual cucumber fruits. Physiologia Plantarum, Copenhagen, v.87, p.313-320, 1993.

SALISBURY, F.B.; ROSS, C.W. Plant physiology. $4^{\text {th }}$ edition, Belmont: Wardsworth Publishing, 1992. 682p.

STIGTER, H.C.M. de. Growth relations between individual fruits, and between fruits and roots in cucumber. Netherlands Journal of Agriculture Science, Den Burg, v.17, p.209-214, 1969.

SULEIMAN, F.; SUWWAN, M.A. Effect of agritone on fruit set and productivity of summer squash (Cucurbita pepo L.) under plastic house conditions. Advances in Horticultural Science, v.4, n.2, p.83-89, 1990. (Resumo em CAB Abstracts on CDROM, 1990-91)

TAIZ, L.; ZEIGER, E. Plant physiology. $3{ }^{\text {rd }}$ edition. Sinauer Associates, 2002. 690p.

WITTWER, S.H. Vegetables. In: NICKELL, L.G. (Ed). Plant growth regulating chemicals. Florida: CRS Press, 1983. v.2, p.213-231. 